Alma Mater Studiorum - Università di Bologna DEPARTMENT OF ECONOMICS

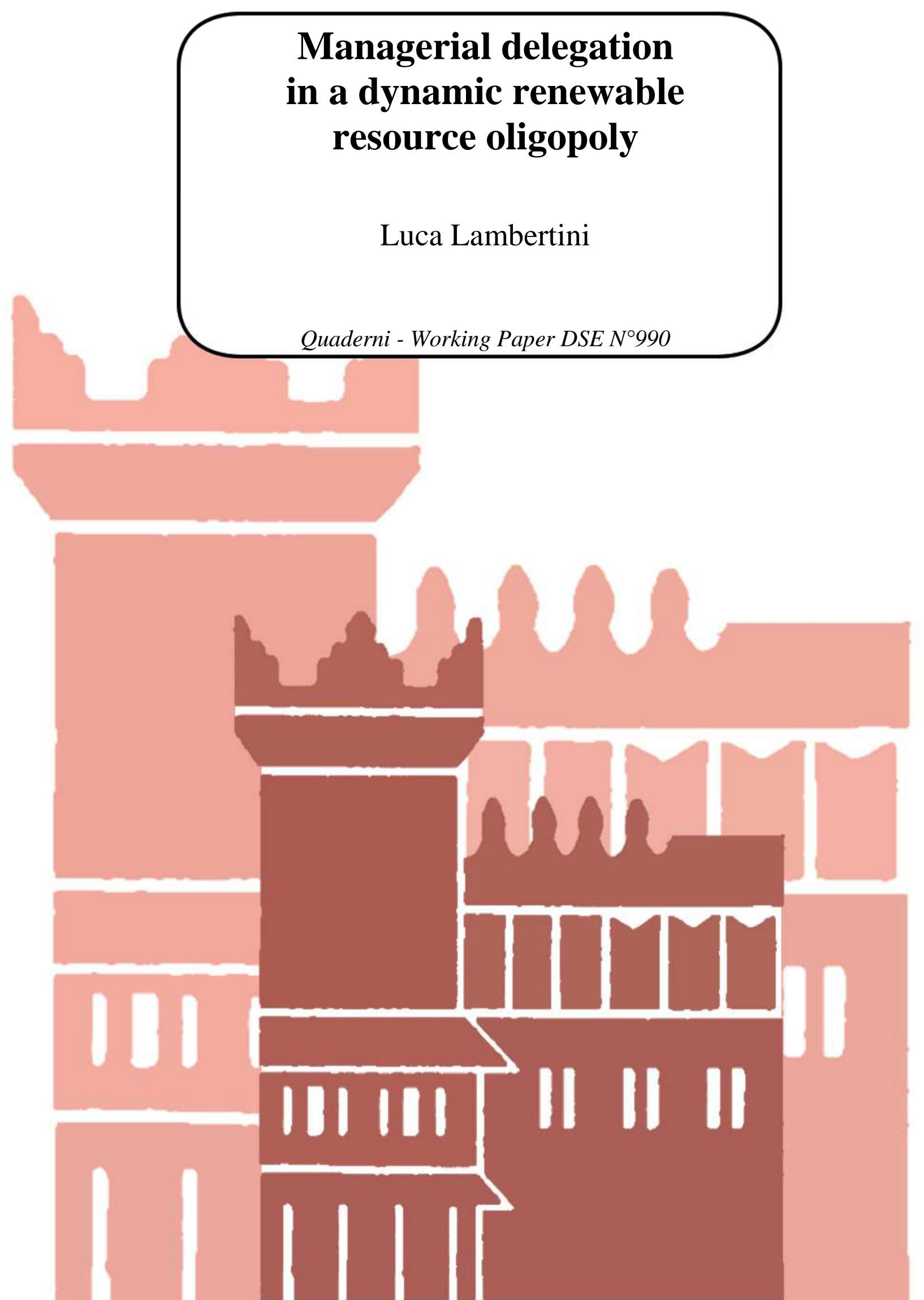




\title{
Managerial delegation in a dynamic renewable resource oligopoly
}

\author{
Luca Lambertini \\ Department of Economics, University of Bologna \\ Strada Maggiore 45, 40125 Bologna, Italy; luca.lambertini@unibo.it
}

January 22, 2015

\begin{abstract}
I propose a differential oligopoly game of resource extraction under (quasi-static) open-loop and nonlinear feedback strategies, where firms are managerial and two alternative types of delegation contract are considered. Under open-loop information, delegation expands the residual steady state resource stock. Conversely, under nonlinear feedback information the outcome depends on the structure of managerial incentives. If sales are used, once again delegation favours resource preservation. On the contrary, if market shares are included in the delegation contract, this combines with an underlying voracity effect in shrinking the steady state volume of the resource.
\end{abstract}

JEL codes: C73, L13, Q2

Keywords: dynamic oligopoly, delegation, renewable resources, feedback strategies 


\section{Introduction}

One of the most debated issue in environmental and resource economics is the joint exploitation of common pool resources and the related tragedy of commons. ${ }^{1}$ Some recent extensions of the literature on this matter examines the exploitation of a renewable resource in differential oligopoly games with profit-seeking firms, i.e., pure entrepreneurial units (Benchekroun, 2003, 2008; Fujiwara, 2008, 2011; Colombo and Labrecciosa, 2013, 2015; and Lambertini and Mantovani, 2014). However, casual observation reveals that in many industries, most of the firms (in particular large ones) are indeed managerial entities in which control is separate from ownership and managers in charge of determining their respective firms' strategies receive remunerations based on combinations of profits and some other magnitudes, such as sales, revenues or market shares.

Most of the extant literature on strategic delegation (based on Vickers, 1985; Fershtman and Judd, 1987; Sklivas, 1987; and Fershtman, Judd and Kalai, 1991) neatly points out that delegation relying on contracts based on sales or revenues favours output expansion on the part of managers, thereby making firms more aggressive as compared to what they would be if directly led by shareholders. This, in turn, produces a more competitive outcome

\footnotetext{
${ }^{1}$ See the seminal contributions by Gordon (1954) and Hardin (1968). The subsequent literature includes, among many others, Levhari and Mirman (1980), Clemhout and Wan (1985), Clark (1990), Benhabib and Radner (1992), Dockner and Sorger (1996), Dawid and Kopel (1997), Sorger (1998) and Benchekroun and Long (2002), among many others. Advanced overviews of the early stages of this debate are in Dasgupta and Heal (1979) and Clark (1990). A recent survey of differential games of resource extraction is in Lambertini (2013, ch. 9).
} 
with a lower price and a higher industry output. These results, attained in static models, are confirmed by the dynamic version of such games, as in Cellini and Lambertini (2008). One notable exception is Ritz (2008), in which the manager's remuneration is a combination of profits and market share. In such a case, the outcome is less competitive than that generated by entrepreneurial firms, all else equal. Hence, there is no a priori presumption that the bearings of separation between ownership and control will be univocal, when the preservation of a natural resource is at stake.

To examine this issue, I am proposing an extension of the differential oligopoly game investigated by Benchekroun (2003, 2008), Fujwara (2008) and Lambertini and Mantovani (2014) to account for two types of delegation contract, one based on sales, the other based on market shares. After outlining the quasi-static outcome generated under open-loop rules, I will set out to consider feedback ones. Given the nonlinear nature of the managerial incentive scheme using market shares, I will consider nonlinear feedback rules only.

The main results of the analysis can be summarised in the following terms. Under open-loop information, delegation increases the residual resource stock surviving at the steady state equilibrium, irrespective of whether the contracts use sales or market shares. Instead, under nonlinear feedback rules, the impact of delegation on the residual stock strictly depends on the specification of the contract. If it features sales, the consequences of delegation are qualitatively the same as under open-loop information. Otherwise, if market shares are used as managerial incentives, the residual stock shrinks as compared to its surviving volume if firms were run by shareholders. 
This contrasting outcome arising when rules more sophisticated than open-loop ones are adopted call for an explanation. This can be identified resorting to the so-called voracity effect (Lane and Tornell, 1996; Tornell and Lane, 1999) operating for sufficiently high levels of the resource growth rate, whereby higher growth rates lead to lower steady state resource stocks, because of the resulting hastening of the extraction activity on the part of firms, combined with the usual pre-emption effect associated with feedback rules, whose presence has been abundantly stressed in previous research on differential oligopoly games (see Fershtman and Kamien, 1987; and Reynolds, 1987). Therefore, the use of market share incentives exerts a flywheel effect in combination with the voracity effect in compromising resource preservation.

The remainder of the paper is organised as follows. Section 2 illustrates the setup. Open-loop equilibria are illustrated in section 3. Nonlinear feedback strategies are dealt with in section 4 . Concluding remarks are in section 5.

\section{The model}

The setup is an extension of Lambertini and Mantovani (2014) and Benchekroun (2008), where a common property productive asset oligopoly is considered, and encompasses the duopoly model used in Benchekroun (2003) and Fujiwara (2008). The model illustrates a differential oligopoly game of resource extraction unravelling over continuous time $t \in[0, \infty)$. The market is supplied by $n$ firms producing a homogeneous good, whose inverse demand function is $p=a-Q$ at any time $t$, with $Q=\sum_{i=1}^{n} q_{i}$. Firms share the same 
technology, characterised by marginal cost $c \in(0, a)$, constant over time. Firms operate without any fixed costs. During production, each firm exploits a renewable natural resource, whose accumulation is governed by the following dynamics:

$$
\dot{S}=F(S)-Q
$$

with

$$
F(S)=\left\{\begin{array}{c}
\delta S \forall S \in\left(0, S_{y}\right] \\
\delta S_{y}\left(\frac{S_{\max }-S}{S_{\max }-S_{y}}\right) \forall S \in\left(S_{y}, S_{\max }\right]
\end{array}\right.
$$

where $S$ is the resource stock, $\delta>0$ is its implicit growth rate when the stock is at most equal to $S_{y}$ and $\delta S_{y}$ is the maximum sustainable yield. Taken together, (1-2) imply that (i) if the resource stock is sufficiently small the population grows at an exponential rate; and (ii) beyond $S_{y}$, the asset grows at a decreasing rate. Moreover, $S_{\max }$ is the carrying capacity of the habitat, beyond which the growth rate of the resource is negative, being limited by available amounts of food and space. In the remainder, we will confine our attention to the case in which $F(S)=\delta S$.

Firms play noncooperatively and choose their respective outputs simultaneously at every instant. At $t=0$, each firm hires a manager whose contract specifies the instantaneous objective which the manager has to maximise. Contracts are observable. I will consider here two alternatives:

- Type-I contract. As in Vickers (1985), the instantaneous objective function of manager $i$ is a linear combination of profits and output: ${ }^{2}$

$$
M_{i}=\pi_{i}+\theta q_{i}, \theta>0
$$

\footnotetext{
${ }^{2}$ This contract is equivalent to that considered in Fershtman and Judd (1987), where
} 
In the remainder, I will treat $\theta$ as a constant for the sake of simplicity. It is worth noting that this type of contract implies that, through delegation, the owners intend to affect the manager's perception of marginal cost, inducing the latter to act as if his firm's marginal cost were indeed lower than $c$. To appreciate how this sort of technological illusion operates, it suffices to observe that (3) can be rewritten as follows:

$$
M_{i}=\pi_{i}+\theta q_{i}=(a-Q-c+\theta) q_{i}=(a-Q-\widehat{c}) q_{i}
$$

where $\widehat{c}=c-\theta$. Hence, one could say that the manager behave as if he were maximising the profit function $\pi_{i}=(a-Q-\widehat{c}) q_{i}$, associated to a firm endowed with a more efficient technology. In a similar way, one could say that any $\theta>0$ induces the manager to behave as if the reservation price were higher than it actually is, say, $A=a+\theta$. Be that as it may, this contract induces the output expansion constituting the core of Vicker's model of strategic delegation.

- Type-II contract. As in Ritz (2008), the instantaneous objective function of manager $i$ is a linear combination of profits and market share:

$$
\begin{gathered}
M_{i}=\pi_{i}+\phi \frac{q_{i}}{Q}, \phi \in(0, \widehat{\phi}), \\
\widehat{\phi} \equiv \frac{(a-c)^{2}(\delta-n r)^{2}}{4 r(n-1)[2 \delta-r(n+1)]}
\end{gathered}
$$

Also in this case, I will treat $\phi$ as a constant. Here, however, $\phi$ does not simply modify the manager's perception of marginal production cost, because of the nonlinear form of the delegation contract.

the maximand is a weighted average of profits and revenues, $M_{i}=\alpha \pi_{i}+(1-\alpha) R_{i}$, $R_{i}=p q_{i}$. A proof of the equivalence is in Lambertini and Trombetta (2002). 
In either setting, the $i$-th manager maximises the following discounted payoff flow

$$
\Pi_{i}=\int_{0}^{\infty} M_{i} e^{-r t} d t
$$

under the constraint posed by the state equation

$$
\dot{S}=\delta S-Q
$$

Parameter $r>0$ is the discount rate, common to all managers and constant over time. Obviously, if $\phi=\theta=0$, firms are pure profit-seeking entrepreneurial units and the two cases coincide.

The analysis will be carried out under the following assumption:

\section{Assumption $1 \delta>n r$.}

This guarantees the positivity of the residual resource stock at the steady state under feedback rules. That is, in the remainder I will leave the possibility of resource exhaustion due to an excessively large number of firms out of the picture, in order to focus solely on the effects of delegation. ${ }^{3}$

If firms don't internalise the consequences of their behaviour at any time and play the individual (static) Cournot-Nash output $q^{C N}=(a-c) /(n+1)$ at all times, then the residual amount of the natural resource in steady state is $S^{C N}=n(a-c) /[\delta(n+1)]=Q^{C N} / \delta$. For future reference, it is worth noting that the static solution corresponds to the open-loop steady state one, which in this game is unstable (see Figure 1 in Fujiwara, 2008, p. 218;

\footnotetext{
${ }^{3}$ The analysis of this specific aspect in the corresponding model without any form of delegation can be found in Lambertini and Mantovani (2014, pp. 119-21).
} 
and Lambertini, 2013, p. 240). The initial condition is $S(0)=S_{0}$, with

$$
S_{0}>\max \left\{\frac{n(a-c+\theta)}{\delta(n+1)}, \frac{n(a-c)+\sqrt{n^{2}(a-c)^{2}+4 \phi\left(n^{2}-1\right)}}{2(n+1) \delta}\right\}
$$

where

$$
\frac{n(a-c+\theta)}{\delta(n+1)}>\frac{n(a-c)+\sqrt{n^{2}(a-c)^{2}+4 \phi\left(n^{2}-1\right)}}{2(n+1) \delta}
$$

for all

$$
\phi \in\left(0, \frac{n^{3}(a-c+\theta)[(a-c)(n-1)+n \theta]}{n^{2}-1}\right)
$$

while the opposite applies outside this interval. Condition (8) suffices to guarantee $S>0$ at all times under the static Cournot-Nash strategies.

\section{Open-loop equilibria}

In either case, since the present game is a linear state one, the open-loop solution is subgame perfect (or strongly time consistent) as it yields a degenerate feedback equilibrium. ${ }^{4}$ It remains true, however, that under open-loop information firms do not internalise the impact of their activities on the productive asset being exploited.

\subsection{Type-I contract}

Under a delegation contract à la Vickers (1985), the current-value Hamiltonian of firm $i$ is:

$$
\mathcal{H}_{i}=(p-c+\theta) q_{i}+\lambda_{i} \dot{S}=
$$

\footnotetext{
${ }^{4}$ For more on the arising of strongly time consistent equilibria in differential games solved under open-loop information, see Fershtman (1987), Mehlmann (1988, ch. 4), Dockner et al. (2000, ch. 7) and Cellini et al. (2005).
} 


$$
=(\sigma-Q) q_{i}+\lambda_{i}(\delta S-Q)
$$

where $\sigma \equiv a-c+\theta>0$ denotes the measure of market size as perceived by the manager of firm $i$.

The necessary conditions (FOCs) are:

$$
\frac{\partial \mathcal{H}_{i}}{\partial q_{i}}=\sigma-2 q_{i}-Q_{-i}-\lambda_{i}=0
$$

where $Q_{-i} \equiv \sum_{j \neq i} q_{j}$, and the adjoint equation reads as follows:

$$
\dot{\lambda}_{i}=(r-\delta) \lambda_{i}
$$

which reveals that $\lambda_{i}=0$ at all times is an admissible solution. This illustrates that firms do not care about the consequences of their activities on the resource stock and behave in a quasi-static way all over the time horizon of the game, playing the optimal output associated with the Cournot-Nash equilibrium $(C N)$ at any time $t$, which can be directly obtained by imposing the symmetry condition $q_{i}=q$ for all $i$ and then solve the FOC (11):

$$
q_{I}^{C N}=\frac{\sigma}{n+1}
$$

where subscript $I$ indicates the structure of the delegation contract.

The resulting steady state stock is

$$
S_{I}^{C N}=\frac{n q_{I}^{C N}}{\delta}=\frac{n \sigma}{(n+1) \delta}
$$

Now observe that

$$
\frac{\partial S_{I}^{C N}}{\partial \theta}=\frac{\partial S_{I}^{C N}}{\partial \sigma}=\frac{n}{(n+1) \delta}>0
$$

This implies: 
Lemma 1 Under a type-I contract and open-loop (quasi-static) rules, any increase in the extent of delegation increases the residual stock of resources in steady state, all else equal.

\section{$3.2 \quad$ Type-II contract}

Assume now the contract offered to managers is à la Ritz (2008). If so, the Hamiltonian of manager $i$ looks as follows:

$$
\begin{gathered}
\mathcal{H}_{i}=(p-c) q_{i}+\phi \frac{q_{i}}{Q}+\lambda_{i} \dot{S}= \\
=\left(a-c-Q-\frac{\phi}{Q}\right) q_{i}+\lambda_{i}(\delta S-Q)
\end{gathered}
$$

Once again, the game exhibits a linear state structure, and therefore the open-loop solution is subgame perfect. The necessary conditions (FOCs) are:

$$
\frac{\partial \mathcal{H}_{i}}{\partial q_{i}}=a-c-2 q_{i}-Q_{-i}-\lambda_{i}+\frac{\phi Q_{-i}}{Q^{2}}=0
$$

where $Q_{-i} \equiv \sum_{j \neq i} q_{j}$, and the adjoint equation reads as follows:

$$
\dot{\lambda}_{i}=(r-\delta) \lambda_{i}
$$

Using the same procedure as in the previous case, we may set $\lambda_{i}=0$, impose symmetry on output levels across the population of firms and solve the first order condition to obtain:

$$
q_{I I}^{C N}=\frac{n(a-c)+\sqrt{n^{2}(a-c)^{2}+4 \phi\left(n^{2}-1\right)}}{2 n(n+1)}>0
$$


everywhere. ${ }^{5}$ The resulting steady state stock of the natural resource is

$$
S_{I I}^{C N}=\frac{n q_{I I}^{C N}}{\delta}=\frac{n(a-c)+\sqrt{n^{2}(a-c)^{2}+4 \phi\left(n^{2}-1\right)}}{2(n+1) \delta}
$$

Once again, it is apparent that $\partial S_{I I}^{C N} / \partial \phi>0$, which entails:

Lemma 2 Under a type-II contract and open-loop (quasi-static) rules, any increase in the extent of delegation increases the residual stock of resources in steady state, all else equal.

In summary, the message delivered by the quasi-static open-loop formulation of the game is that the myopia associated with such rules, combined with managerial delegation, has positive consequences on the preservation of the natural resource, and in fact it is amplified by delegation. Additionally, this holds for any number of firms, that is, $S_{I}^{C N}$ and $S_{I I}^{C N}$ are strictly positive for all $n$.

\section{Nonlinear feedback equilibria}

Since a type-II contract gives rise to a nonlinear problem due to the form of the managerial objective, for the sake of comparability I will concentrate on nonlinear feedback strategies in both cases, following Tsutsui and Mino (1990), Shimomura (1991), Fujiwara (2008) and Lambertini and Mantovani (2014). Again, my attention will be restricted to symmetric equilibria.

\footnotetext{
${ }^{5}$ The alternative root can be disregarded as it is negative over the entire parameter range.
} 


\subsection{Type-I contract}

This case can be quickly dealt with, as it is a relatively straightforward generalisation of the setup investigated in Lambertini and Mantovani (2014). The Hamilton-Jacobi-Bellman equation writes as:

$$
r V_{i}(S)=\max _{q_{i}}\left[(a-c+\theta-Q) q_{i}+V_{i}^{\prime}(S)(\delta S-Q)\right]
$$

where $V_{i}(S)$ is the firm $i$ 's value function; and $V_{i}^{\prime}(S)=\partial V_{i}(S) / \partial S$. The first order condition (FOC) on $q_{i}$ is

$$
a-c+\theta-2 q_{i}-\sum_{j \neq i} q_{j}-V_{i}^{\prime}(S)=0
$$

In view of the ex ante symmetry across firms, we impose the condition $q_{j}=q_{i}=q(S)$ and solve the FOC (22) to obtain $V^{\prime}(S)=a-c+\theta-(n+$ 1) $q(S)$. Substituting this into (21) yields an identity in $S$. Differentiating both sides with respect to $S$ and rearranging terms, any feedback strategy is implicitly given by the following differential equation:

$$
q^{\prime}(S)=\frac{(\delta-r)[a-c-\theta-(n-1) q(S)]}{(a-c-\theta)(n-1)+\delta(n+1) S-2 n^{2} q(S)},
$$

which must hold together with terminal condition $\lim _{t \rightarrow \infty} e^{-r t} V(s)=0$.

To characterise nonlinear feedback strategies one has to choose, in the space $(S, q(S))$, the specific solution identified by the tangency point between the curve describing output $q(S)$ and the line $\dot{S}=0$ (cf. Fujiwara, 2008, p. 218). As a first step, observe that, along $\dot{S}=0, q(S)=\delta / n$, while at the tangency point, $q^{\prime}(S)=\delta / n$. Using this two expressions, (23) can be rewritten as follows:

$$
\frac{\delta}{n}=\frac{(\delta-r)[a-c-\theta-\delta(n-1) S / n]}{(a-c-\theta)(n-1)+\delta(n+1) S-2 n^{2} \delta S / n}
$$


The above equation can be solved w.r.t. $S$, to obtain

$$
S_{I}^{N L F}=\frac{(a-c+\theta)(\delta-n r)}{\delta[2 \delta-r(n+1)]}=\frac{n q_{I}^{N L F}}{\delta}
$$

with $S_{I}^{N L F}>0$ under Assumption $1,{ }^{6}$ and $\partial S_{I}^{N L F} / \partial \theta>0$ in the entire parameter range in which $S_{I}^{N L F}$ is positive. ${ }^{7}$ As expected, it is easily checked that (21-25) coincide with the corresponding expressions appearing in Lambertini and Mantovani (2014, section 3.2, pp. 118-19) if firms are entrepreneurial units, i.e., $\theta=0$.

The foregoing discussion can be summarised in

Lemma 3 Under a type-I delegation contract and nonlinear feedback rules, any increase in the extent of delegation increases the residual stock of resources in steady state, for all $n>\max \{1, \delta / r\}$.

So far, the analysis of the resource exploitation game seems to consistently confirm that delegation is beneficial in terms of the preservation of the resource itself in steady state, even considering strategies more sophisticated than those associated with open-loop information. This, however, is a deceptive impression generated by the simplistic delegation structure based on output expansion, as we are about to see by examining the incentive contract based on market shares.

\footnotetext{
${ }^{6}$ Note that $n r>(n+1) r / 2$ for all $n, r>0$.

${ }^{7}$ The initial amount of resource must be lower than $S_{N L F}^{*}$ in order for $q_{N L F}^{*}$ to be an equilibrium strategy (see Itaya and Shimomura, 2001; Rubio and Casino, 2002).
} 


\subsection{Type-II contract}

If managerial incentives relies on market shares, the Hamilton-Jacobi-Bellman equation of firm $i$ is the following:

$$
r V_{i}(S)=\max _{q_{i}}\left[(a-c-Q) q_{i}+\phi \frac{q_{i}}{Q}+V_{i}^{\prime}(S)(\delta S-Q)\right]
$$

The first derivative w.r.t. $q_{i}$, under the symmetry condition $q_{i}=q(S)$ for all $i$, is:

$$
a-c-(n+1) q(S)-V^{\prime}(S)+\frac{\phi(n-1)}{n^{2} q(S)}=0
$$

which delivers

$$
V^{\prime}(S)=\frac{n^{2}[a-c-(n+1) q(S)] q(S)-\phi(n-1)}{n^{2} q(S)}
$$

After substituting the above expression into (26) and differentiating w.r.t. $S$, we have:

$$
q^{\prime}(S)=\frac{(\delta-r) q(S)\left[\phi(n-1)+n^{2} q(S)(a-c-(n+1) q(S))\right]}{\delta \phi(n-1) S+n^{2} q^{2}(S)\left[(a-c)(n-1)+\delta(n+1) S-2 n^{2} q(S)\right]}
$$

In correspondence of the tangency point associated with the nonlinear

solution, $q(S)=\delta S / n$ and $q^{\prime}(S)=\delta / n$, so that (29) can be rewritten as follows:

$$
\frac{\phi(n+1) r-\delta[(a-c)(\delta-n r)+\delta((n+1) r-2 \delta) S] S}{n(n+1)[\sigma(a-c-\delta S) S+\phi]}=0
$$

whose roots are

$$
S=\frac{(a-c)(\delta-n r) \pm \sqrt{(a-c)^{2}(\delta-n r)^{2}-4(n-1) r[2 \delta-(n+1) r] \phi}}{2 \delta[2 \delta-(n+1) r]}
$$


The smaller solution, $S_{-}$, can be disregarded for two equally relevant reasons. The first is that, if delegation were not adopted (i.e., $\phi=0$ ), $S_{-}=0$, which does not solve (2) under the assumption of nonlinear feedback strategies. The second, perhaps equally if not more compelling, is that setting $\phi=\theta=0$ must yield the solution attained by Lambertini and Mantovani (2014, eq. (19), p. 119) for pure profit-seeking entrepreneurial firms, which happens only if one takes $S_{+}$. Accordingly, the steady state equilibrium resource stock under nonlinear feedback rules and managerial incentives based on market shares is

$S_{I I}^{N L F}=\frac{(a-c)(\delta-n r)+\sqrt{(a-c)^{2}(\delta-n r)^{2}-4(n-1) r[2 \delta-(n+1) r] \phi}}{2 \delta[2 \delta-(n+1) r]}$

which belongs to $\mathbb{R}^{+}$for all $\phi \in(0, \widehat{\phi}]$ and $\delta>n r$.

The above expression exhibits the following property:

$$
\frac{\partial S_{I I}^{N L F}}{\partial \phi}=-\frac{(n-1) r \sqrt{(a-c)^{2}(\delta-n r)^{2}-4(n-1) r[2 \delta-(n+1) r] \phi}}{\delta\left[(a-c)^{2}(\delta-n r)^{2}-4(n-1) r(2 \delta-(n+1) r) \phi\right]}<0
$$

for all $n>1$, which can be spelled out in the following:

Lemma 4 Under a type-II delegation contract and nonlinear feedback rules, any increase in the extent of delegation decreases the residual stock of resources in steady state, for all $\phi \in(0, \widehat{\phi}]$ and $\delta>n r$.

Jointly considering Lemmas 3 and 4 reveals that feedback rules (in this case, nonlinear ones) have opposite implications depending on the incentive scheme being specified by firms' owners in the contract offered to their managers. 
The results appearing in Lemmata 3-4 have some relevant bearings on the discussion about the so-called voracity effect (see Lane and Tornell, 1996; and Tornell and Lane, 1999), which can be briefly summarised by saying that, in principle, one would expect that the higher the resource growth rate is, the higher should be volume of that resource in steady state. However, this may not hold true as firms respond to any increase in the growth rate by hastening resource extraction, whereby one observes that $\partial S / \partial \delta<0$ in steady state, at least for sufficiently high levels of $\delta$. The arising of such voracity effect has been highlighted, with pure profit-seeking units, in Benchekroun (2008) and Lambertini and Mantovani (2014). In particular, Lambertini and Mantovani (2014, p. 121) show that under nonlinear feedback information the voracity effect operates if, in absence of any form of delegation,

$$
\delta>r\left[n+\sqrt{\frac{n(n+1)}{2}}\right]
$$

with the expression on the r.h.s. of (34) being higher than $n r$. Here, the presence of two different types of managerial delegation has opposite effects also in relation with the voracity effect, since the following holds:

Proposition 5 If delegation is based on the sales volume (as in Vickers, 1985), then managerial incentives soften the voracity effect, if the latter operates. If instead delegation is based on market shares (as in Ritz, 2008), then managerial incentives amplify the voracity effect, when the latter is operating, or replace it if it is not present.

It is now worth looking back at the open-loop solution to note that, at the resulting quasi-static Cournot equilibrium, both types of delegation mitigate 
the voracity effect. Put differently, one could say that a linear delegation scheme softens any underlying voracity effect irrespective of the informational content underpinning firms' strategies. It is only when nonlinear delegation contracts and more sophisticated rules are adopted that a synergy between delegation and voracity appears. This, indeed, is in line with the acquired wisdom holding that feedback rules make agents more aggressive, each one trying to pre-empt the rivals. ${ }^{8}$

A last remark is in order. The foregoing analysis appears to imply that the specific design of delegation contracts proposed to managers is of public interest not only for the usual reasons connected with consumer surplus and profits but also for (perhaps more far-reaching) motives dealing with the impact of the separation between ownership and control on resource (and species) preservation.

\section{Concluding remarks}

I have investigated the implications of the separation between ownership and control in a differential oligopoly game where firms exploit a renewable resource over an infinite horizon. Two alternative structures of the delegation contract have been considered, either à la Vickers (1985), whereby each manager maximises an objective consisting in a weighted sum of profit and output, or profits and market share à la Ritz (2008).

The foregoing analysis has shown that while under open-loop strategies

\footnotetext{
${ }^{8}$ This idea is pervasive in the literature treating differential oligopoly games with quantity competition (Driskill and McCafferty, 1989); capacity accumulation (Reynolds, 1987, 1991); sticky prices (Fershtman and Kamien, 1987; Cellini and Lambertini, 2004).
} 
delegation favours the preservation of the resource in steady state, under nonlinear feedback rules this applies only to linear contracts à la Vickers (1985), because the effect of delegation in such a case is equivalent to either an increase in market size or a decrease in marginal cost, and therefore any increase in the extent of delegation has a positive impact on the residual volume of the natural resource surviving at the steady state. Conversely, the contract based on market shares appears to exert a negative impact on the same magnitude, acting as a flywheel in an undesirable synergy with the voracity effect originally singled out by Lane and Tornell (1996). The policy implication stemming from these findings is that a public environmental agency should pay the due attention to the internal organization of firms heavily involved in the exploitation of key resources, when regulating access to such resources. 


\section{References}

[1] Benchekroun, H. (2003). Unilateral production restrictions in a dynamic duopoly. Journal of Economic Theory 111, 214-39.

[2] Benchekroun, H. (2008). Comparative dynamics in a productive asset oligopoly. Journal of Economic Theory 138, 237-61.

[3] Benchekroun, H. and Long, N.V. (2002). Transboundary fishery: a differential game model. Economica 69, 207-21.

[4] Benhabib, J. and Radner, R. (1992). The joint exploitation of productive asset: a game-theoretic approach. Economic Theory 2, 155-90.

[5] Cellini, R. and Lambertini, L. (2004). Dynamic oligopoly with sticky prices: closed-loop, feedback and open-loop solutions. Journal of Dynamical and Control Systems 10, 303-14.

[6] Cellini, R. and Lambertini, L. (2008). Product and process innovation in differential games with managerial firms, in R. Cellini and L. Lambertini (eds), The Economics of Innovation: Incentives, Cooperation, and R\&D Policy, Bingley, Emerald Publishing, 159-76.

[7] Cellini, R., Lambertini, L. and Leitmann, G. (2005). Degenerate feedback and time consistency in differential games, in E.P. Hofer and E. Reithmeier (eds), Modeling and Control of Autonomous Decision Support Based Systems. Proceedings of the 13th International Workshop on Dynamics and Control, Aachen, Shaker Verlag, 185-92. 
[8] Clark, C.W. (1990). Mathematical Bioeconomics: The Optimal Management of Renewable Resources, New York, Wiley.

[9] Clemhout, S. and Wan Jr., H. (1985). Dynamic common property resources and environmental problems. Journal of Optimization Theory and Applications 46, 471-81.

[10] Colombo, L. and Labrecciosa, P. (2013). Oligopoly exploitation of a private property productive asset. Journal of Economic Dynamics and Control, 37, 838-53.

[11] Colombo, L. and Labrecciosa, P. (2015). On the Markovian efficiency of Bertrand and Cournot equilibria. Journal of Economic Theory 155, $322-58$.

[12] Dasgupta, P.S. and G.M. Heal (1979), Economic Theory and Exhaustible Resources, Cambridge, Cambridge University Press.

[13] Dawid, H. and Kopel, M. (1997). On the economically optimal exploitation of a renewable resource: the case of a convex environment and a convex return function. Journal of Economic Theory 76, 272-97.

[14] Dockner, E.J., Jørgensen, S., Long, N.V. and Sorger, G. (2000). Differential Games in Economics and Management Science, Cambridge, Cambridge University Press.

[15] Dockner, E.J. and Sorger, G. (1996). Existence and properties of equilibria for a dynamic game on productive assets. Journal of Economic Theory 171, 201-27. 
[16] Driskill, R. and McCafferty, S. (1989). Dynamic duopoly with adjustment costs: A differential game approach. Journal of Economic Theory, 49, 324-38.

[17] Fershtman, C. (1987). Identification of classes of differential games for which the open-loop is a degenerate feedback Nash equilibrium", Journal of Optimization Theory and Applications, 55, 217-31.

[18] Fershtman, C. and Judd, K. (1987). Equilibrium incentives in oligopoly. American Economic Review, 77, 927-40.

[19] Fershtman, C., Judd, K. and Kalai, E. (1991). Observable contracts, strategic delegation and cooperation. International Economic Review, 32, 551-59.

[20] Fershtman, C. and Kamien, M. (1987). Dynamic duopolistic competition with sticky prices. Econometrica 55, 1151-64.

[21] Fujiwara, K. (2008). Duopoly can be more anti-competitive than monopoly. Economics Letters 101, 217-19.

[22] Fujiwara, K. (2011). Losses from competition in a dynamic game model of a renewable resource oligopoly. Resource and Energy Economics, 33, $1-11$.

[23] Gordon, H.S. (1954). The economic theory of a common-property resource: the fishery. Journal of Political Economy, 62, 124-42.

[24] Hardin, G. (1968). The tragedy of the commons. Science 162, 1243-48. 
[25] Itaya, J. and Shimomura, K. (2001). A dynamic conjectural variations model in the private provision of public goods: a differential game approach. Journal of Public Economics 81, 153-72.

[26] Lambertini, L. (2013). Oligopoly, the Environment and Natural Resources, London, Routledge.

[27] Lambertini, L. and Mantovani, A. (2014). Feedback equilibria in a dynamic renewable resource oligopoly: pre-emption, voracity and exhaustion", Journal of Economic Dynamics and Control, 47, 115-22.

[28] Lambertini, L. and Trombetta, M. (2002). Delegation and firms' ability to collude. Journal of Economic Behavior and Organization, 47, 359-73.

[29] Lane, P.R. and Tornell, A. (1996). Power, growth, and the voracity effect. Journal of Economic Growth 1, 213-41.

[30] Levhari. D. and Mirman, L. (1980). The great fish war: an example using a dynamic Cournot-Nash solution, Bell Journal of Economics 11, $322-34$.

[31] Mehlmann, A. (1988). Applied Differential Games, New York, Plenum Press.

[32] Reynolds, S. (1987). Preemption and commitment in an infinite horizon model. International Economic Review 28, 69-88.

[33] Reynolds, S. (1991). Dynamic oligopoly with capacity adjustment costs. Journal of Economic Dynamics and Control 15, 491-514. 
[34] Ritz, R. (2008). Strategic incentives for market share. International Journal of Industrial Organization, 26, 586-97.

[35] Rubio, S.J., and Casino, B. (2002). A note on cooperative versus noncooperative strategies in international pollution control. Resource and Energy Economics 24, 251-61.

[36] Shimomura, K. (1991). The feedback equilibria of a differential game of capitalism. Journal of Economic Dynamics and Control 15, 317-38.

[37] Sklivas, S. (1987). The strategic choice of management incentives. RAND Journal of Economics, 18, 452-58.

[38] Sorger, G. (1998). Markov-perfect Nash equilibria in a class of resource games. Economic Theory 11, 79-100.

[39] Tornell, A. and Lane, P.R. (1999). The voracity effect. American Economic Review 89, 22-46.

[40] Tsutsui, S., and Mino, K. (1990). Nonlinear strategies in dynamic duopolistic competition with sticky prices. Journal of Economic Theory $\mathbf{5 2}, \mathbf{1 3 6 - 6 1 .}$

[41] Vickers, J. (1985). Delegation and the theory of the firm. Economic Journal (Conference Supplement), 95, 138-47. 


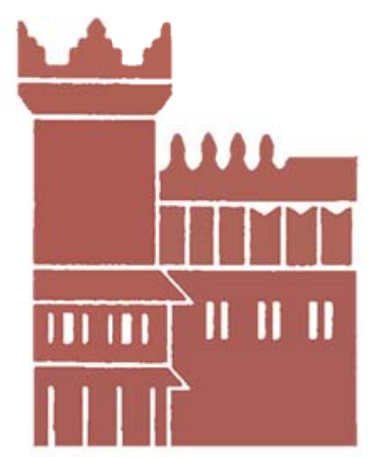

Alma Mater Studiorum - Università di Bologna DEPARTMENT OF ECONOMICS

Strada Maggiore 45

40125 Bologna - Italy

Tel. +39051 2092604

Fax +390512092664

http://www.dse.unibo.it 